\title{
Study on the Product Formation of the Reaction between Criegee Compound and Propargyl Radical
}

Nghiên cứu sự tạo thành sản phẩm của phản ứng giữa hợp chất Criegee với gốc Propargyl

\author{
Tien V. Pham \\ Hanoi University of Science and Technology, Hanoi, Vietnam \\ Email: tien.phamvan@hust.edu.vn
}

\begin{abstract}
Mechanism of the reaction between Criegee compound $\left(\mathrm{CH}_{2} \mathrm{OO}\right)$ and Propargyl radical $\left(\mathrm{C}_{3} \mathrm{H}_{3}\right)$ has been studied by using the density functional theory DFT/M06-2X in conjunction with the 6-311++G(3df,2p) basis set for both optimization and single-point energy calculations. The calculated results indicate that mechanism of the $\mathrm{C}_{3} \mathrm{H}_{3}+\mathrm{CH}_{2} \mathrm{OO}$ reaction can occur in two different directions: $\mathrm{H}$-atom abstraction and/or addition. As a result, 11 various products have been created from this reaction; in which, $\mathrm{P} 10(\mathrm{OCHCHCHCHO}+\mathrm{H})$ is the most thermodynamically stable product and the reaction path leading to the $\mathrm{P} 7\left(\mathrm{CH}_{2}-[\mathrm{cyc}-\mathrm{CCHCHOO}]+\mathrm{H}\right)$ product is the most energetically and kinetically favorable channel.
\end{abstract}

Keywords: DFT, $\mathrm{C}_{3} \mathrm{H}_{3}, \mathrm{M06}-2 \mathrm{X}, 6-311++(3 \mathrm{df}, 2 \mathrm{p})$

Tóm tắt

Cơ chế của phản ứng giữa hợp chất Criegee $\left(\mathrm{CH}_{2} \mathrm{OO}\right)$ với gốc Propargyl $(\mathrm{C} 3 \mathrm{H} 3)$ đã được nghiên cứu bằng cách sử dụng lý thuyết phiếm hàm mật độ DFT/M06-2X kết hợp với bộ cơ sở 6-311++G(3df,2p) để tối ưu hóa và tính toán năng lượng điểm đơn. Kết quả tính toán chỉ ra rằng cơ chế của phản ứng $\mathrm{C}_{3} \mathrm{H}_{3}+\mathrm{CH}_{2} \mathrm{OO}$ có thể xảy ra theo hai hướng khác nhau: tách nguyên tử $H$ hoặc cộng hợp. Kết quả là, 11 sản phẩm khác nhau đã được tạo ra từ phản ứng này; trong đó, $\mathrm{P} 10(\mathrm{OCHCHCHCHO}+\mathrm{H})$ là sản phẩm bền nhất về mặt nhiệt động và đường phản ứng dẫn đến sản phẩm $\mathrm{P} 7\left(\mathrm{CH}_{2}-[\mathrm{cyc}-\mathrm{CCHCHOO}]+\mathrm{H}\right)$ là kênh thuận lợi nhất về mặt năng lượng và động học.

Từ khóa: DFT, $\mathrm{C}_{3} \mathrm{H}_{3}, \mathrm{M06}-2 \mathrm{X}, 6-311++\mathrm{G}(3 \mathrm{df}, 2 \mathrm{p})$

\section{Introduction}

Criegee compounds [1] are known to be carbonyl oxides generated in the ozonolysis of unsaturated hydrocarbons; their atmospheric fate plays a vital role in determining the oxidative effect of the atmosphere and its ability for free radical generation and secondary organic aerosol formation [2]. In the atmosphere, Criegee can interact with atmospheric species such as $\mathrm{H}_{2} \mathrm{O}, \mathrm{SO}_{2}, \mathrm{HCOOH}$, and $\mathrm{C}_{3} \mathrm{H}_{3}$ and unimolecular isomerization and decomposition to create $\mathrm{OH}$ [2]. Inferences about the roles of Criegee compounds were originally based on indirectly predicted rate coefficients, and there has been no consensus on whether the crucial reaction of stabilized Criegee species in the troposphere is with propargyl radicals [2,3]. Propargyl radicals have been found to be available in flames with an amount of abundance because they are very stable in the pyrolysis process and their reactions with molecular oxygen occur slowly [4]. In terms of structure, propargyl radical has two isomer configurations known as $\mathrm{CH}_{2}-\mathrm{C} \equiv \mathrm{CH}$ and $\mathrm{CH}_{2}=\mathrm{C}=\mathrm{CH}$. Each frame contains a single electron in an orbital at the head or terminal carbon atom and two weak $\pi$ bonds. The reactivity of the propargyl radical with species in the troposphere is therefore predicted to be extremely high. It is worth noting that exploring the reaction of Criegee compound with propargyl radical is especially critical because of the abundance of propargyl radical in the atmosphere and due to the bimolecular reactions of stabilized Criegee species in the atmosphere are the major processes in the formation of aerosols [5,6], which scatter sunlight and affect earth's radiative balance [7]. In particular, the oxidation of sulfur dioxide via stabilized Criegee species is an important source of sulfuric acid [8], which plays a crucial role in aerosol nucleation.

To our best knowledge, so far, no studies have been performed on the reaction of Criegee compound with propargyl radical. Hence, in order to have a more comprehensive view of this reaction, its mechanism will be examined thoroughly in this study based on the structures of all species involved which were optimized at the M06-2X/6-311++G(3df,2p) level of theory and single-point energy calculations at the same level. The next study will provide new insight into how the dominant atmospheric reaction processes of the

ISSN: 2734-9381

https://doi.org/10.51316/jst.153.etsd.2021.31.4.14

Received: December 17,2020; accepted: February 18, 2021 
Criegee compound vary with altitude, depending on temperature and pressure. Thus, the results in this and further papers are of interest both for atmospheric chemistry and computational chemistry.

\section{Computational Methods}

The density functional theory (DFT) with the common M06-2X [9,10] functional in conjunction with the $6-311++\mathrm{G}(3 \mathrm{df}, 2 \mathrm{p})$ basis set were used to figure out the mechanism for the title reaction. In this work, the geometries optimized by the M06-2X/6$311++\mathrm{G}(3 \mathrm{df}, 2 \mathrm{p})$ method were utilized for the establishment of the potential energy surface (PES). The correlative parameters including vibrational frequencies, moments of inertia, and zero-point vibrational energies (ZPVE) were obtained at the same method. All species in the system were classified based on their vibrational analysis. Of which, the local minima such as reactants, intermediates, and products have all positive frequencies while each saddle point like a transition state contains an imaginary frequency. The intrinsic reaction coordinate (IRC) $[11,12]$ predictions were employed to verify the validity of transition states. The M06-2X/6-311++G(3df,2p) relative energies of all points were then refined by the single-point energy calculations using the M06-2X/6$311++\mathrm{G}(3 \mathrm{df}, 2 \mathrm{p})+$ ZPVEs level of theory. The ZPVE values were corrected by a factor of 0.971 . The Gaussian 16 software package was utilized to optimize and compute single-point energies for all species in this system.

\section{Results and Discussions}

As stated above, all species involved in the title reaction were optimized at the M06-2X/6$311++\mathrm{G}(3 \mathrm{df}, 2 \mathrm{p})$ level of theory. The detailed mechanism of the system describing all reaction channels is graphically plotted in Fig. 1. It is easy to see that many bimolecular products including 4 molecular products (P1, P3, P8, and P11) and 7 radical products $(\mathrm{P} 2, \mathrm{P} 4, \mathrm{P} 5, \mathrm{P} 6, \mathrm{P} 7, \mathrm{P} 9$, and $\mathrm{P} 10)$ can be formed when $\mathrm{CH}_{2} \mathrm{OO}$ attacks propargyl radicals.

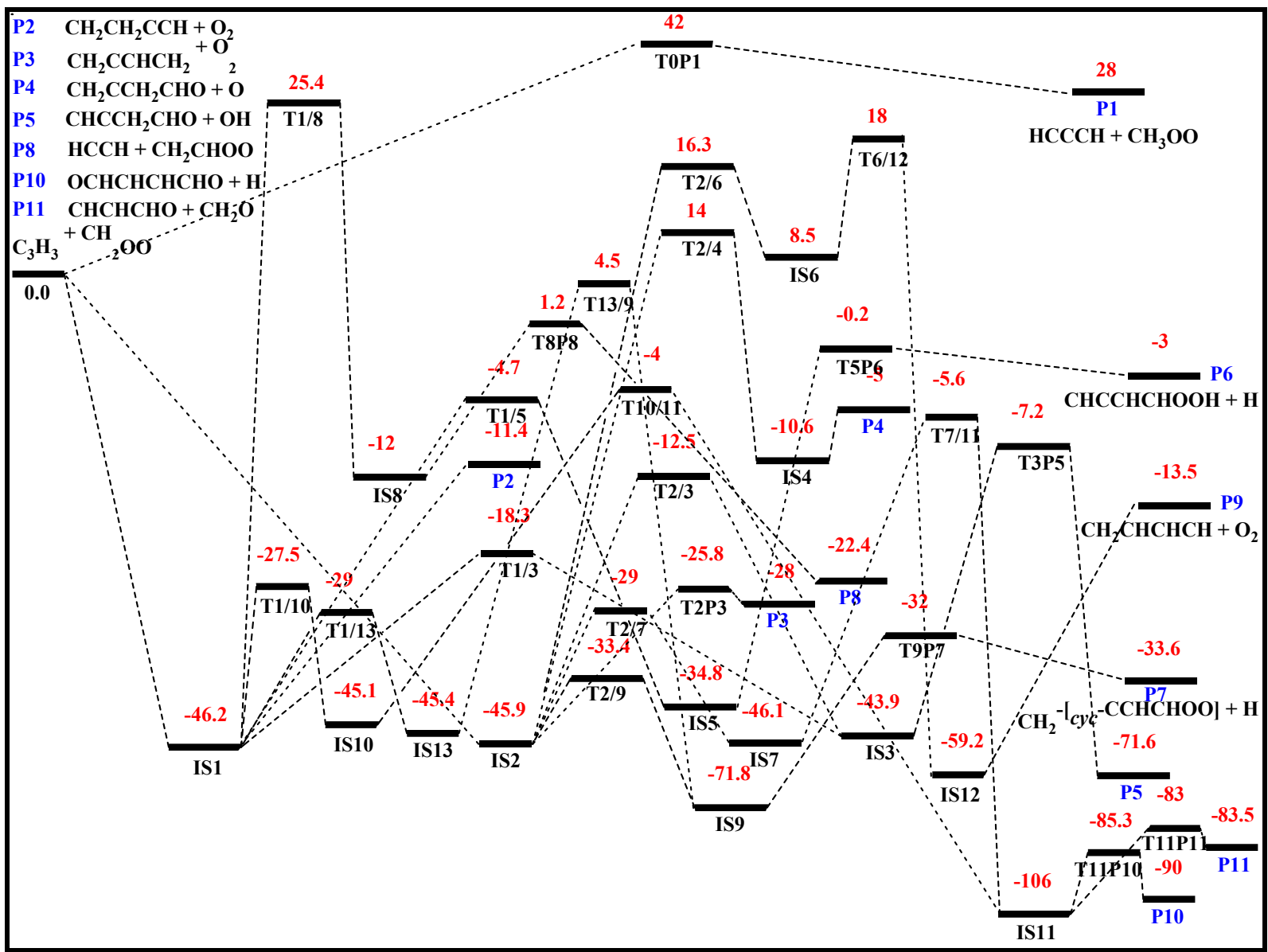

Fig. 1. The potential energy surface of the $\mathrm{CH}_{2} \mathrm{OO}+\mathrm{C}_{3} \mathrm{H}_{3}$ reaction calculated at the M06-2X/6-311++G(3df,2p) + ZPVE level of theory. (Energies are in units of $\mathrm{kcal} / \mathrm{mol}$ ). 
From those products, the $\mathrm{P} 1\left(\mathrm{HCCCH}+\mathrm{CH}_{3} \mathrm{OO}\right)$ radical product was generated by the $\mathrm{H}$-abstraction channel going via the TOP1 transition state located at an energy level of $42 \mathrm{kcal} / \mathrm{mol}$ above the reactants, while other products were created by the addition channels going through two main adducts, namely IS1 and IS2 as shown in Fig. 1. The T0P1 geometric structure optimized at the M06-2X method shows that a hydrogen atom is abstracting from the $\mathrm{CH}_{2}$ group of propargyl radical at the distance of $1.5 \AA$ and is coming to the $\mathrm{CH}_{2} \mathrm{OO}$ carbon atom at the loose bond length of $1.2 \AA$. This abstraction is characterized by an imaginary frequency of $\sim 1100 \mathrm{i} \mathrm{cm}^{-1}$ existing in the T0P1 harmonic oscillator modes.

The two adducts, IS1 $\left(\mathrm{CHCCH}_{2} \mathrm{CH}_{2} \mathrm{O}_{2}\right)$ and IS2 $\left(\mathrm{CH}_{2} \mathrm{CCHCH}_{2} \mathrm{O}_{2}\right)$, can supply many isomers and/or final products P2 - P11 via the isomerization and/or the direct dissociation/decomposition processes. It should be noted that the two addition channels leading to IS1 and IS2 are both barrierless reaction paths and these two isomers have similar formation probability due to their relative energies are the same values of -46.2 and $-45.9 \mathrm{kcal} / \mathrm{mol}$, respectively. The $\mathrm{P} 2$ product can be directly created from IS1 by cutting off the C-O bond without going through any first-order saddle point. The oxygen molecule together with the linear radical $\mathrm{CH}_{2} \mathrm{CH}_{2} \mathrm{CCH}$ holds an energy level of over $11 \mathrm{kcal} / \mathrm{mol}$ below the entrance channel. In addition to P2, five other isomer products namely IS3, IS5, IS8, IS10, and IS13 have also been directly produced from IS1 by the isomerization processes of IS1 $\rightarrow$ IS3, IS1 $\rightarrow$ IS5, IS1 $\rightarrow$ IS8, IS1 $\rightarrow$ IS10, IS1 $\rightarrow$ IS13 proceeding via the transition states $\mathrm{T} 1 / 3, \mathrm{~T} 1 / 5, \mathrm{~T} 1 / 8$, $\mathrm{T} 1 / 10$, and $\mathrm{T} 1 / 13$ with relative energies of $-18.3,-4.7$, $25.4,-27.5$, and $-29 \mathrm{kcal} / \mathrm{mol}$, respectively. It is not difficult to realize that $\mathrm{T} 1 / 8$ is the highest saddle point compared to the four remaining ones, thus the IS8 isomer and $\mathrm{P} 8\left(\mathrm{C}_{2} \mathrm{H}_{2}+\mathrm{CH}_{2} \mathrm{CHOO},-22.4 \mathrm{kcal} / \mathrm{mol}\right)$ are less favorable products of the title reaction. If three isomers IS3 $(-43.9 \mathrm{kcal} / \mathrm{mol})$, IS5 $(-34.8 \mathrm{kcal} / \mathrm{mol})$, and IS8 $(-12 \mathrm{kcal} / \mathrm{mol})$ are generated by the H-shift processes, the two isomers IS10 (a six-membered ring) and IS13 (a five-membered ring) are produced by the ring-closure processes. These two ring structures have the same formation probability because their relative energies are -45.1 and $-45.4 \mathrm{kcal} / \mathrm{mol}$ and the two transition states $\mathrm{T} 1 / 10$ and $\mathrm{T} 1 / 13$ connecting them with the IS1 adduct are also similar, being -27.5 and $-29 \mathrm{kcal} / \mathrm{mol}$, respectively. The two radical products $\mathrm{P} 5\left(\mathrm{OH}+\mathrm{CHCCH}_{2} \mathrm{CHO}\right)$ and $\mathrm{P} 6(\mathrm{CHCCHCHOOH}+$ $\mathrm{H})$ were created after forming the IS3 and IS5 intermediates. The first product was formed by the decomposition process, IS3 $\rightarrow$ P5, occurring via the T3P5 transition state located at $7.2 \mathrm{kcal} / \mathrm{mol}$ below the singlet entrance point, while the second one was produced by the IS5 $\rightarrow$ P6 dissociation process going through the T5P6 transition state situated at the $-0.2 \mathrm{kcal} / \mathrm{mol}$ energy level, $c f$. Fig. 1 . Compared to the reaction path forming the P6 product, the reaction channel forming the P5 one is more advantageous in energy due to the energy barrier heights of T1/5 and T5P6 on the first channel are larger than those of T1/3 and T3P5 on the second channel (41.5 and 34.6 vs. $~ 28$ and $36.7 \mathrm{kcal} / \mathrm{mol}$ ). Accordingly, the $\mathrm{P} 5$ product is also more sustainable than the P6 product (-71.6 vs. $-3 \mathrm{kcal} / \mathrm{mol}$ ). Two other intermediates IS9 and IS11 were also created from IS10 and IS13 via the saddle points $\mathrm{T} 10 / 11$ and $\mathrm{T} 13 / 9$, respectively. The T10/11 is the transition state of a 2,3-H-shift with the distances $\mathrm{C}(2)-\mathrm{H}$ and $\mathrm{C}(3)-\mathrm{H}$ of 1.3 and $1.32 \AA$, respectively, characterized by an imaginary frequency of $1706 \mathrm{~cm}^{-1}$, while the T13/9 is the transition state of a 1,3-H-shift process with the distances $\mathrm{C}(1)-\mathrm{H}$ and $\mathrm{C}(2)-\mathrm{H}$ of 1.47 and $1.42 \AA$, respectively, described by a negative frequency of $2288 \mathrm{i} \mathrm{cm}^{-1}$.

From IS2 $\left(\mathrm{CH}_{2} \mathrm{CCHCH}_{2} \mathrm{O}_{2}\right)$, similarly, five isomers (IS3, IS4, IS6, IS7, IS9) and the P3 final product can be directly produced by the isomerization and decomposition processes IS2 $\rightarrow$ IS3, IS2 $\rightarrow$ IS4, IS2 $\rightarrow$ IS6, IS2 $\rightarrow$ IS7, IS2 $\rightarrow$ IS9, and IS2 $\rightarrow$ P3 going via the transition states $\mathrm{T} 2 / 3, \mathrm{~T} 2 / 4, \mathrm{~T} 2 / 6, \mathrm{~T} 2 / 7$, $\mathrm{T} 2 / 9$, and T2P3 with relative energies of $-12.5,14$, $16.3,-29,-33.4$, and $-25.8 \mathrm{kcal} / \mathrm{mol}$, respectively. Of those transition states, the T2/4 and T2/6 ones take up very high relative energy values in comparison with the remaining ones. Hence, the isomers IS4, IS6, IS12 and the bimolecular products $\mathrm{P} 4$ and $\mathrm{P} 9$ are considered to be less favorable. IS12 $(-59 \mathrm{kcal} / \mathrm{mol})$ was formed from the IS6 $\rightarrow$ IS12 isomerization process via the T6/12 transition state with the $18 \mathrm{kcal} / \mathrm{mol}$ energy level above the entrance channel. Both the channels going from IS4 to P4 and from IS12 to P9 are the barrierless exit reaction paths with the dissociation energies of 5.6 and $45.7 \mathrm{kcal} / \mathrm{mol}$, respectively, calculated at the M06$2 \mathrm{X} / 6-311++\mathrm{G}(3 \mathrm{df}, 2 \mathrm{p})$ level of theory. This indicates that either O-loss or $\mathrm{O}_{2}$-loss lead to the final radical products as $\mathrm{P} 4$ and $\mathrm{P} 9$. The $\mathrm{P} 4\left(\mathrm{CH}_{2} \mathrm{CCH}_{2} \mathrm{CHO}+\mathrm{O}\right)$ product is more favorable than the $\mathrm{P} 9\left(\mathrm{CH}_{2} \mathrm{CHCHCH}\right.$ $+\mathrm{O}_{2}$ ) product because the saddle points $\mathrm{T} 2 / 6$ and T6/12 on the channel forming P9 are higher than the T2/4 transition state on the path producing P4. However, the P4 is less thermodynamically stable than the $\mathrm{P} 9$ by about $8.5 \mathrm{kcal} / \mathrm{mol}(-5 \mathrm{vs} .-13.5 \mathrm{kcal} / \mathrm{mol})$. Both channels proceeding from the reactants $\left(\mathrm{C}_{3} \mathrm{H}_{3}+\right.$ $\mathrm{CH}_{2} \mathrm{OO}$ ) to $\mathrm{P} 4$ and $\mathrm{P} 9$ are exothermic processes. The IS3 isomer is generated from IS1 via the T1/3 saddle point as mentioned above, it is also produced from IS2 through the T2/3 transition state. Although both T1/3 and $\mathrm{T} 2 / 3$ display a movement of a hydrogen atom from the $\mathrm{CH}_{2}$ group to the outermost oxygen atom, the relative energy of the former TS is nearly $6 \mathrm{kcal} / \mathrm{mol}$ lower than the latter TS, indicating that the IS1 $\rightarrow$ IS3 process is made easier than the IS2 $\rightarrow$ IS3 channel. After forming the cyclic intermediate state known as IS7 ( $\mathrm{cyc}-\mathrm{CH}_{2} \mathrm{CCHCH}_{2} \mathrm{OO},-46.1 \mathrm{kcal} / \mathrm{mol}$ ), the isomer IS11 $\left(\mathrm{OCH}_{2} \mathrm{CHCHCHO},-106 \mathrm{kcal} / \mathrm{mol}\right)$ was also 
created by the ring-opening process via the $\mathrm{T} 7 / 11$ transition state located at the energy of $5.6 \mathrm{kcal} / \mathrm{mol}$ under the reactants. The T7/11 contains only one imaginary frequency of $1675.3754 \mathrm{i} \mathrm{cm}^{-1}$ corresponding to two simultaneous processes of a 1,2- $\mathrm{H}$-shift and an $\mathrm{O}-\mathrm{O}$ bond breaking with the bond lengths $\mathrm{C}(1)-\mathrm{H}, \mathrm{C}(2)-\mathrm{H}$, and $\mathrm{O}-\mathrm{O}$ recorded at the transition structure as $1.32,1.33$, and $1.52 \AA$, respectively. The IRC scanning result which is graphically plotted in Fig. 2 shows that T7/11 is connecting between the IS7 and IS11 intermediates.

As stated above, the IS11 isomer can be created by the IS1 $\rightarrow$ IS10 $\rightarrow$ IS1 1 isomerization instead of the IS2 $\rightarrow$ IS7 $\rightarrow$ IS11 channel. These two channels are competitive with one another due to the transition state which they have to pass hold the same energy levels, $\mathrm{T} 1 / 10(-27.5 \mathrm{kcal} / \mathrm{mol}) \sim \mathrm{T} 2 / 7(-29 \mathrm{kcal} / \mathrm{mol})$ and $\mathrm{T} 10 / 11(-4 \mathrm{kcal} / \mathrm{mol}) \sim \mathrm{T} 7 / 11(-5.6 \mathrm{kcal} / \mathrm{mol})$.

The radical product $\mathrm{P} 10(\mathrm{OCHCHCHCHO}+\mathrm{H})$ and the bimolecular product P11 (CHCHCHO $+\mathrm{CH}_{2} \mathrm{O}$ ) have been established just after forming the IS11 intermediate. If the $\mathrm{P} 10$ product has to overcome the T11P10 transition state, the P11 product must proceed via the T11P11 first-order saddle point. As can be seen from Fig. 1, those TSs are dog-eat-dog with each other because the T11P11 relative energy value is only $2 \mathrm{kcal} / \mathrm{mol}$ higher than the T11P10 energy level $(-83$ vs. $-85.3 \mathrm{kcal} / \mathrm{mol})$. Therefore, their formation probability is considered to be the same in ordinary conditions of temperature and pressure. In addition, the P10 is the most stable production energy and its relative energy value is lower than that of the P11 product about $6.5 \mathrm{kcal} / \mathrm{mol}$ computed at the M06$2 \mathrm{X} / 6-311++\mathrm{G}(3 \mathrm{df}, 2 \mathrm{p})$ level of theory. The last isomer IS9 can be generated both from IS1 via (T1/13, T13/9) and IS2 via T2/9 as mentioned above. Because the energy level of T13/9 is larger than that of T2/9 about $38 \mathrm{kcal} / \mathrm{mol}$ ( $4.5 \mathrm{vs} .-33.4 \mathrm{kcal} / \mathrm{mol})$, indicating that the IS2 $\rightarrow$ IS9 isomerization process is more favorable than the IS1 $\rightarrow$ IS13 $\rightarrow$ IS9 channel. From the IS9 intermediate state, the $\mathrm{P} 7$ product can be formed by the IS9 $\rightarrow$ P7 dissociation process going via the tight T9P7 transition state holding only one negative frequency of $\sim 552 \mathrm{i} \mathrm{cm}{ }^{-1}$. The geometric structure of T9P7 reveals that one hydrogen atom is leaving far away from the $\mathrm{CH}_{2}$ group in the five-membered ring of IS9 at the long distance of about 2.1 angstrom. This process needs to be supplied activation energy of approximately 40 $\mathrm{kcal} / \mathrm{mol}$ to pass over the position of the T9P7 saddle point to come to the $\mathrm{P} 7$ radical product. It is worth noting that the channel starting from the $\mathrm{C}_{3} \mathrm{H}_{3}+\mathrm{CH}_{2} \mathrm{OO}$ point via two isomers (IS2, IS9) and two transition states (T2/9, T9P7) to the $\mathrm{P} 7$ product is the most energetically and kinetically favorable channel and it is also an exothermic reaction path with the energy released by about $34 \mathrm{kcal} / \mathrm{mol}$. The structures of all species involved in this channel are therefore selected to display in Fig. 3.

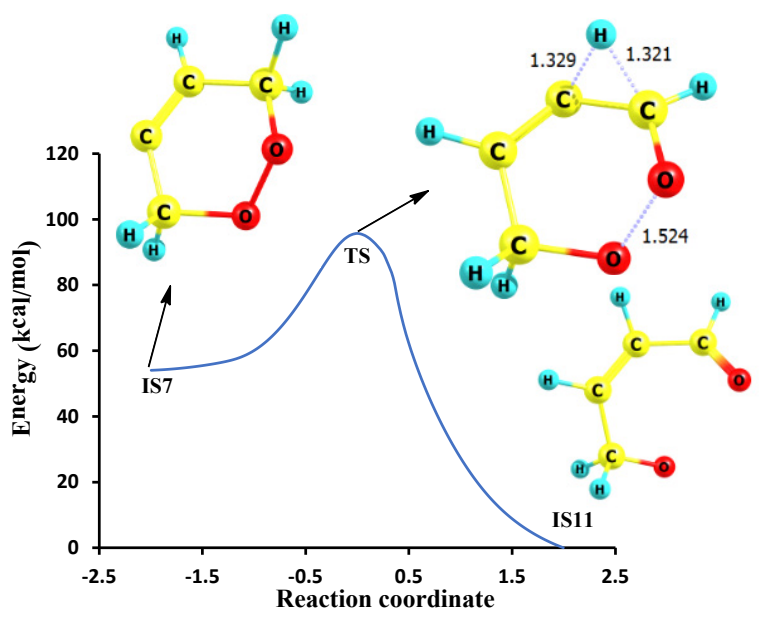

Fig. 2. IRC of the T7/11 transition state
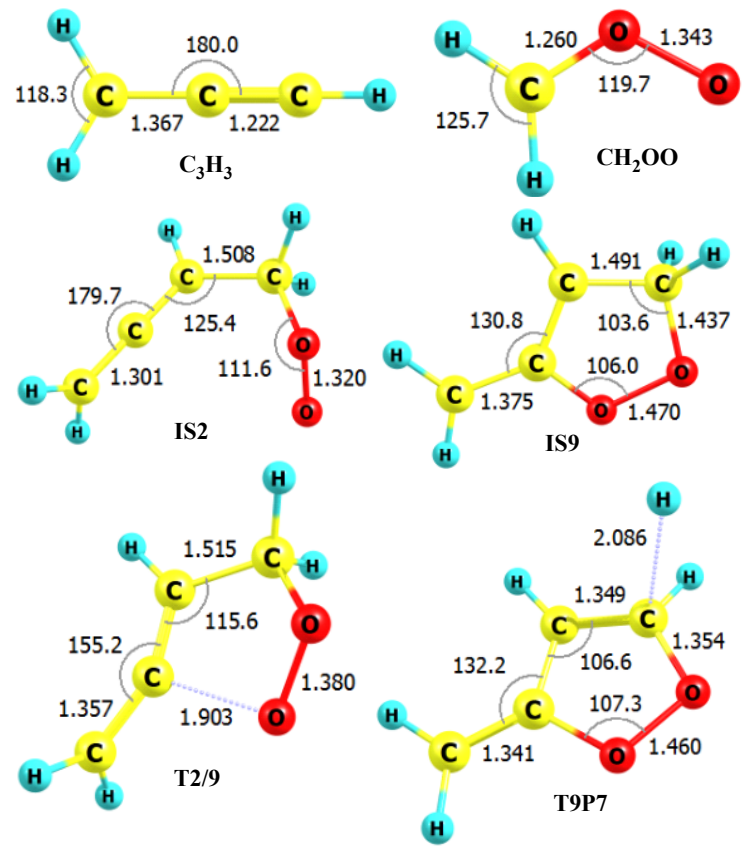

Fig. 3. Geometric structures of all species on the most favorable channel of the $\mathrm{C}_{3} \mathrm{H}_{3}+\mathrm{CH}_{2} \mathrm{OO}$ reaction optimized at the M06-2X/6-311++G(3df,2p) level of theory.

To enhance the reliability of this study, the relative energies of all bimolecular products of the title reaction were compared to the experimental reported data cited from two reliable database resources NIST and ATcT as shown in Table 1. It can be seen that all values predicted in the present work are about $3-6 \mathrm{kcal} / \mathrm{mol}$ lower than the available literature data from NIST and ATcT, which are suitable due to the deviation of the M06-2X method was proved to be about 5 - $6 \mathrm{kcal} / \mathrm{mol}$ in comparison with experimental data. However, for further kinetic calculations, those values should be refined at a high level of theory such as $\operatorname{CCSD}(\mathrm{T})$ or CASSPT2. 
Table 1. Comparison between the present relative energy values and the available literature data.

\begin{tabular}{|c|c|c|}
\hline Products & This study & NIST/ATcT \\
\hline P1 & 28.0 & $33.2 \pm 1.2$ \\
\hline P2 & -11.4 & $-8.5 \pm 1.9$ \\
\hline P3 & -28.0 & $-25.6 \pm 2.0$ \\
\hline P4 & -5.0 & $-1.5 \pm 1.3$ \\
\hline P5 & -71.6 & $-65.2 \pm 0.2$ \\
\hline P6 & -3.0 & $1.2 \pm 0.5$ \\
\hline P7 & -33.6 & $-29.5 \pm 1.3$ \\
\hline P8 & -22.4 & $-16.2 \pm 2.1$ \\
\hline P9 & -13.5 & $-8.7 \pm 0.8$ \\
\hline P10 & -90.0 & $-85.3 \pm 1.1$ \\
\hline P11 & -83.5 & $-78.9 \pm 1.4$ \\
\hline
\end{tabular}

\section{Conclusion}

In the present theoretical study, the potential energy surface for the $\mathrm{CH}_{2} \mathrm{OO}+\mathrm{C}_{3} \mathrm{H}_{3}$ reaction has been mapped out. The reactants, intermediate states, transition structures, and products of this reaction were optimized by using density functional theory M06-2X with the $6-311++G(3 d f, 2 p)$ basis set. Single-point energies for all species involved were also computed at the same level as shown in Fig. 1. The constructed detailed PES shows that the mechanism of the title reaction contains 11 main channels and many subchannels, 13 intermediate states, 24 transition states, and 11 bimolecular products. The mechanism also reveal that only one reaction path proceeds via $\mathrm{H}$ abstraction process leading to the bimolecular product $\mathrm{P} 1\left(\mathrm{HCCCH}+\mathrm{CH}_{2} \mathrm{OO}\right)$, the remaining channels occur via an addition mechanism resulting in the P2 - P11 products. The most stable product, $\mathrm{OCHCHCHCHO}+$ $\mathrm{H}$, and the lowest channel in energy, $\mathrm{C}_{3} \mathrm{H}_{3}+\mathrm{CH}_{2} \mathrm{OO}$ $\rightarrow \mathrm{IS} 2 \rightarrow \mathrm{IS} 9 \rightarrow \mathrm{P} 7 \mathrm{CH}_{2}$-[cyc-CCHCHOO] $+\mathrm{H}$, were also identified in this study. The relative energies of all products were also compared with the available literature values collected from NIST and ATcT, which indicates that the present results are in reasonable agreement with the NIST/ATcT values. The predicted data of this work will be a reliable reference for further theoretical and experimental investigations in the near future.

\section{References}

[1] R. Criegee, Mechanism of ozonolysis, Angew. Chem. Int. Ed. Engl., 14, 745-752, 1975 https://doi.org/10.1002/anie.197507451

[2] D. Johnson, G. Marston, The gas-phase ozonolysis of unsaturated volatile organic compounds in the troposphere. Chem. Soc. Rev. 37 (2008) 699-716. https://doi.org/10.1039/b704260b
[3] L. Vereecken, J. S. Francisco, Theoretical studies of atmospheric reaction mechanisms in the troposphere. Chem. Soc. Rev. 41 (2012) 6259-6293. https://doi.org/10.1039/c2cs35070j

[4] I. R. Slagle, D. Gutman, Kinetics of the reaction of $\mathrm{C}_{3} \mathrm{H}_{3}$ with molecular oxygen from 293-900 K, Symp. Int. Combust. Vol. 21 (1988) pp. 875-883. https://doi.org/10.1016/S0082-0784(88)80319-9

[5] Y. Sakamoto, S. Inomata, J. Hirokawa, Oligomerization reaction of the Criegee intermediate leads to secondary organic aerosol formation in ethylene ozonolysis, J. Phys. Chem. A, 117 (2013) 12912-12921. https://doi.org/10.1021/jp408672m

[6] J. H. Kroll, J. S. Clarke, N. M. Donahue, J. G. Anderson, Mechanism of $\mathrm{HO}_{\mathrm{x}}$ formation in the gasphase ozone-alkene reaction. 1. direct, pressuredependent measurements of prompt $\mathrm{OH}$ yields, J. Phys. Chem. A 105 (2001) 1554-1560. https://doi.org/10.1021/jp002121r

[7] J. H. Kroll, S. R. Sahay, J. G. Anderson, K. L. Demerjian, N. M. Donahue, Mechanism of $\mathrm{HO}_{\mathrm{x}}$ formation in the gas-phase ozone-alkene reaction. 2. prompt versus thermal dissociation of carbonyl oxides to form OH, J. Phys. Chem. A 105 (2001) 4446-4457. https://doi.org/10.1021/jp004136v

[8] Y. Zhao, D. G. Truhlar, A new local density functional for main-group thermochemistry, transition metal bonding, thermochemical kinetics, and noncovalent interactions, J. Chem. Phys. 125 (2006) 194101-1 194101-18. https://doi.org/10.1063/1.2370993

[9] Y. Zhao, D. G. Truhlar, Density functional for spectroscopy: no long-range self-interaction error, good performance for rydberg and charge-transfer states, and better performance on average than B3LYP for ground states, J. Phys. Chem. A 110 (2006) 1312613130. https://doi.org/10.1021/jp066479k

[10] G. E. Scuseria, C. L. Janssen, H. F. Schaefer III, An efficient reformulation of the closed-shell coupled cluster single and double excitation (CCSD) equations, J. Chem. Phys. 89 (1998) 7382-7387. https://doi.org/10.1063/1.455269

[11] C. Gonzalez, H. B. Schlegel, An improved algorithm for reaction path following, J. Chem. Phys. 90 (1989) 2154-2161. https://doi.org/10.1063/1.456010

[12] C. Gonzalez, H. B. Schlegel, Reaction path following in mass-weighted internal coordinates, J. Chem. Phys. 94 (1990) 5523-5527. https://doi.org/10.1021/j100377a021 